-Minireview

\title{
Roles of NF- $\mathrm{kB}$ in central nervous system damage and repair
}

\author{
Li YANG, Lu-Yang TAO, Xi-Ping CHEN \\ Department of Forensic Sciences, Soochow University, Laboratory of Aging and Nerves Diseases Soochow University, \\ Suzhou 215123, China
}

\begin{abstract}
NF- $\kappa \mathrm{B}$ family is a kind of nuclear factors in B lymphocyte that can bind to the immunoglobulin $\kappa$-chain enhancer and enhance transcriptional activity. NF- $\mathrm{BB} /$ Rel proteins, as a dimeric transcription factor, control the expression of genes that regulate a broad range of biological processes through canonical and non-canonical pathways. In the central nervous system, NF- $\kappa \mathrm{B}$ controls inflammatory reactions and the apoptotic cell death following nerve injury. It also contributes to the infarction and cell death in stroke models and patients. However, NF- $\kappa \mathrm{B}$ is essential for neurosurvival as well. NF- $\kappa \mathrm{B}$ activation is a part of recovery process that may protect neurons against oxidative-stresses or brain ischemia-induced apoptosis and neurodegeneration. Inhibition of NF- $\kappa \mathrm{B}$ may reduce its neuroprotection activity. Hence the dual opposite effects of NF- $\kappa$ B on cells. The ultimate survival or death of neurons depends on which, where and when the NF- $\kappa B$ factors are activated.
\end{abstract}

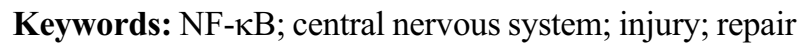

\section{Introduction}

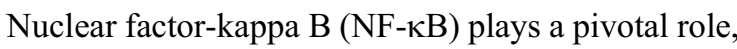
especially in nervous system, in controlling inflammation, immune responses, cellular differentiation, and apoptosis. $\mathrm{NF}-\kappa \mathrm{B} /$ Rel proteins, as a dimeric transcription factor, control the expression of the genes that regulate a broad range of biological processes through canonical and non-canonical NF- $\kappa \mathrm{B}$ pathways ${ }^{[1]}$. It is also related to learning and memory formation. Mice lacking the NF- $\kappa$ B p50 subunit were not proficient in learning tasks associated with the active avoidance training, an effective learning paradigm ${ }^{[2]}$. Recent genetic models identified a role for NF- $\kappa B$ in protecting neurons against various neurotoxins. The genetic evidence for its involvement in cognition and memory is also emerging now ${ }^{[3]}$. In neurodegenerative diseases, craniocerebral injuries, or oxidative stress, a serial of signals from damaged neurons and glial cells could activate $\mathrm{NF}-\kappa \mathrm{B}$. In the model of aging or neuronal apoptosis, NF- $\kappa \mathrm{B}$

Corresponding author: Xi-Ping CHEN

Tel: 86-512-62185006

Fax: 86-512-65880408

E-mail: xiping.chen@163.com

Article ID: 1673-7067(2007)05-0307-07

CLC number: R74

Document code: A

Received date: 2007-04-02 plays a complicated role in brain repair by controlling cell differentiation, apoptosis, and etc. Emerging evidence supports a key role for NF- $\mathrm{KB}$ as a mediator in transcriptiondependent enduring structral and functional changes in neuronal circuits ${ }^{[4]}$.

Regarding to the contribution of NF- $\kappa \mathrm{B}$ to cell death or survival, controversial results have been reported by many investigators. This article will give an overview of the roles of NF- $\kappa \mathrm{B}$ in neuronal injury and repair in central nervous system (CNS).

\section{$2 \mathrm{NF}-\kappa \mathrm{B}$ and its signaling pathways}

Sen and B

altimore first described NF- $\kappa \mathrm{B}$ as a transcription factor in 1986. NF-kB family is a kind of nuclear factors in B lymphocyte that can bind to the immunoglobulin $\kappa$-chain enhancer to enhance the transcriptional activity, and thus named as nuclear factor $\kappa \mathrm{B}$ or $\kappa$-gene nuclear factor. NF- $\kappa \mathrm{B}$ is widely expressed in all cells including nerve cells, and they can regulate the generation of codocyte factors, growth factors, cell adhesion molecules and some acute protein factors in either healthy or morbid state. NF- $\kappa \mathrm{B}$ is a homodimer or heterodimer complex composed of Rel family proteins p50, p65 (Rel A), c-Rel, p52, and RelB. The most common NF- $\kappa \mathrm{B}$ complex is $\mathrm{P} 65 / \mathrm{P} 50$ heterodimer, which is 
composed of a $65-\mathrm{kDa}$ subunit and a 50-kDa subunit ${ }^{[5]}$.

A number of factors such as cytokine, oxygen free radicals, inspiratory particles, radiation, bacterial toxins and virus could activate NF- $\kappa \mathrm{B}$. In many in vivo models of brain injuries such as cerebral trauma, ischemic, and epileptic attacks induced by kainite, $\mathrm{NF}-\kappa \mathrm{B}$ is robustly activated ${ }^{[6]}$. Usually, NF- $\kappa B$ resides in the endochylema of $\mathrm{G}_{0}$ stage cells, and exists as an inactive form bound by an inhibitory

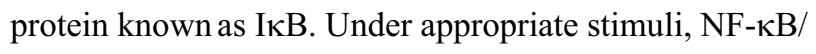
Rel complex was released from the IкB complex due to phosphorylation and ubiquination-dependent degradation of IкB. $\mathrm{NF}-\kappa \mathrm{B} / \mathrm{Rel}$ dimmer transports into the nucleus when it is freed from I $\kappa \mathrm{B}$ complex, and combines with cognate DNA sequences to stimulate target genes' expression. This cascade represents the canonical pathway of NF- $\kappa B$ activation. In the non-canonical pathway, the inactive NF- $\kappa B$ p100/ RelB complexes are held in the cytoplasm. Signals which are mediated by a number of receptors including leukotriene beta (LT- $\beta$ ) receptors, CD40 receptors and B cell-activating factors belonging to the tumor necrosis factor family (BAFF) receptors (BR3) activate NF- $\mathrm{KB}$-inducing kinase (NIK), which

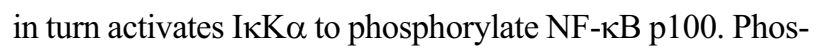
phorylation of the NF- $\mathrm{BB}$ p100 results in its ubiquitination and proteasomal processing to generate NF- $\kappa B$ p52. NF- $\kappa B$ p52/RelB complex translocates to the nucleus and induces target gene expression. This signaling cascade is characterized by the involvement of NIK and I $\mathrm{KK} \alpha$, as well as by the processing of p100 and nuclear translocation of RelB but without NF- $\kappa$ B essential modifier (I $\kappa \mathrm{K}-\gamma / \mathrm{NEMO})^{[7]}$.

A redox mechanism regulates the DNA binding activity of NF- $\kappa$ B. Agents that modify free sulfhydryls such as $N$-ethylmaleimide and diamide inhibit NF-кB's DNA binding activity. On the contrary, reductants such as dithiothreitol (DTT) enhance its DNA binding activity ${ }^{[6]}$.

\section{$3 \quad \mathrm{NF}-\kappa \mathrm{B}$ in CNS injury}

3.1 In ischemic brain injury $\mathrm{NF}-\kappa \mathrm{B}$ binding activity is enhanced in the injured brain area when stroke occurs or blood-supply of the local brain is blocked in the rodents. Researches showed that activation of NF- $\mathrm{BB}$ in the brain may contribute to the infarction and cell death in both pMCAO models and stroke patients ${ }^{[8,9]}$. Other studies, however, showed protective effcts of NF- $\mathrm{KB}$ on neurons. For example, a significant increase of NF- $\kappa \mathrm{B}$ binding activity was observed exclusively in the decussatio pyramidum (DP) as early as $3 \mathrm{~h}$ after is chemia in the hippocampus of gerbil, when other morphological signs of post-ischemic tissue injury had not yet been detected. Following this early enhancement of NF- $\kappa \mathrm{B}$ binding activity, microglia activation was visualized in the CA1 pyramidal region at $24 \mathrm{~h}$ of recovery, by histochemical staining with lectin from Ricinus communis (RCA-120). While, only a moderate increase of glial fibrillary acidic protein (GFAP) was observed in all regions of the hippocampus. This coherent pattern of glial cellular proliferation preserved until 3-4 d post-ischemia, when apoptotic DNA fragmentation in CA1 pyramidal neurons had distinctly been detected by terminal deoxynucleotidyl transferase biotin-dUTP nick end labeling (TUNEL) staining. During this period, NF- $\kappa \mathrm{B}$ binding in the DP also manifested continuous elevation in the abdominal part $(\mathrm{AbP})$ of the hippocampus ${ }^{[10]}$. Researches showed that the proteins involved in NF- $\kappa \mathrm{B}$ signal transduction expressed within 1 week after middle cerebral artery occlusion (MCAO) and trimethyltin (TMT) treatment in the hippocampus. Enhancement of p50 level in neurons and their processes was independent of blood brain barrier compromising. Hippocampal neurons expressing p50 were not stained with FluoroJade until $7 \mathrm{~d}$ post-TMT treatment, indicating that NF- $\kappa \mathrm{B}$ expressed in the survival neurons. Moreover, the persistent $\mathrm{p} 50$ expression during the period of hippocampal neurodegeneration after MCAO suggested that NF-кB could protect neurons from ischemic injury ${ }^{[11,12]}$.

Experimentally and clinically, stroke is followed by both acute and chronic inflammatory responses characterized by production of inflammatory cytokines and infiltration of leukocytes into the brain. NF- $\kappa \mathrm{B}$ controls inflammatory reactions by regulating the expression of inflammatory genes. However, NF- $\kappa \mathrm{B}$ signaling pathway is also involved in regulating the expression of genes implicated in cellular proliferation and apoptosis, including the cellular inhibitors of apoptosis (c-IAP1, c-IAP2, and IXAP). The activation of $\mathrm{NF}-\kappa \mathrm{B}$ reduces the apoptosis in injured cells and ischemic neurons by raising the expression of anti-apoptotic cellular proteins. Thus, drugs or therapies 'targeting' the NF-кB pathway for stroke must reach the equilibrium between suppression of inflammatory responses and interference with neuroprotective pathways ${ }^{[5]}$.

Phosphorylation of $I \kappa \mathrm{B} \alpha$, the key form of I $\mathrm{I} B$ in the brain, can be enhanced at $1 \mathrm{~d}$ after MCAO and TMT treatment and remain elevated for at least one week, suggesting that IKK activity increases. Therefore, NF- $\mathrm{KB}$ appears to play an active role in neuron survival. Signals that activate 
$\mathrm{NF}-\kappa \mathrm{B}$ transcription may cause the phosphorylation and subsequent proteolysis of the inhibitory IкB subunit. After being activated, the released $\mathrm{NF}-\kappa \mathrm{B}$ dimers migrate into the nucleus and interact with the specific DNA sequences of target genes ${ }^{[11]}$.

3.2 In traumatic brain injury (TBI) NF- $\kappa B$ could be activated in the pallium neurons several hours after brain injury in rodents. For instance, in a rat model of cerebral cortex contusion, NF- $\kappa \mathrm{B}$ binding activity in damaged brain increased as early as $3 \mathrm{~h}$, reached to its peak at $72 \mathrm{~h}$, and remained elevated at $7 \mathrm{~d}$ post-TBI ${ }^{[13]}$. The results of human cerebral trauma sample manifested that NF- $\kappa B$ binding activity significantly increased at $12 \mathrm{~h}$; The intensity of immunohistochemical staining of NF- $\kappa \mathrm{B}$ p65 increased gradually, and persisted for at least $20 \mathrm{~d}^{[14]}$. Another research showed that the cells with NF-кB p50 augment survived hippocampal injury ${ }^{[13]}$. Regular expressions of NF-

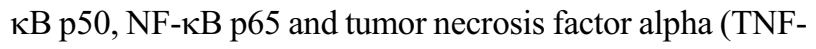
$\alpha$ ) were observed in the mouse brain in each period after experimental thermal ablation injury. The existence of TNF- $\alpha$,

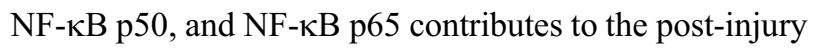
immunoreaction, which is closely associated with the occurrence of secondary insults and the tissue-remodeling process in wound healing. Inappropriate and deregulated activation of NF- $\mathrm{KB}$ in damaged brain tissue may be implicated in development of the secondary brain damage ${ }^{[15]}$. Tamatani et al. prove that TNF protects hippocampal neurons by inducing the expression of $B c l-2$ and $B c l-x$ through $\mathrm{NF}-\kappa \mathrm{B}$. These surveys strengthen the view that NF- $\kappa \mathrm{B}$ can inhibit apoptosis by inducing the expression of antiapoptotic genes $^{[6]}$.

3.3 In induced brain injury A number of factors such as cytokine, drug, oxygen free radicals, ultraviolet radiation, oxygenize and metabolic product, and some bacterial and viral products, can induce neuron death or apoptosis. Glutaredoxin 2 (Grx2) of Escherichia coli or glutaredoxin of human could catalyze glutathione-disulfide oxidoreduction via its -Cys-Pro-Tyr-Cys-active site. NF- $\kappa \mathrm{B}$ activity is extremely important for the survival of cerebellar granule neurons. Grx 2 enters cerebellar granule neurons, and exerts its activity via NF- $\kappa \mathrm{B}$ activation. The DNA binding activity of NF- $\kappa \mathrm{B}$ is also essential for neurosurvival. Overexpression of I $\kappa \mathrm{B}-\Delta \mathrm{N}$ in granule neurons significantly reduces their viability. E. coli and human glutaredoxins protect cerebellar granule neurons from kainic-acid-induced death by increasing the DNA binding activity of NF- $\kappa$ B through Ref-1.
Abrogation of NF- $\mathrm{BB}$, either by deletion of Rel A (p65) or by overexpression of I $\mathrm{I} B-\Delta \mathrm{N}$, sensitizes immune cells to the apoptosis in response to TNF and DNA damaging agents ${ }^{[6]}$. These researches demonstrate the anti-apoptotic role of $\mathrm{NF}-\kappa \mathrm{B}$, which is beneficial to neuronal recovery from injury.

Glutamate may activate a serial of transcription factors by increasing intracellular calcium concentration and/or oxygen free radical production. In turn, these transcription factors amplify the signal by recruiting other genes to dictate specific transcriptional programs, and induce apoptosis. Pretreatment of cultures with aspirin, which inhibits NF- $\kappa$ B activation, or with specific p53 antisense oligonucleotide, which inhibits p53 transcription, completely prevents glutamate-induced p53 induction and apoptosis ${ }^{[16]}$. The glutamate-induced cell death in primary cerebrocortical cultures of mixed neuron and glia could be reduced by creatine, possibly via activation of the Ras/NF- $\kappa B$ system ${ }^{[17]}$. The neuroprotective effect of stem cell factors (SCFs) against glutamate excitotoxicity also could be blocked by pharmacological inhibition of NF- $\mathrm{KB}$ or dominant negative $\mathrm{I} \kappa \mathrm{B}(\mathrm{I} \kappa \mathrm{B}-\Delta \mathrm{N})$. SCF up-regulates the anti-apoptotic genes,

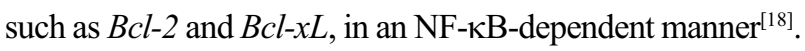
Marini AM et al. found a candidate NF- $\kappa \mathrm{B}$ site in the promoter 3 of brain derived neurotrophy factor (BDNF) gene and showed that $N$-methyl-D-aspartate (NMDA) inotropic glutamate receptors increased BDNF expression through NF- $\kappa$ B-dependent mechanisms, which was essential for NMDA's neuroprotection in vitro ${ }^{[19]}$. TGF- $\beta 1$ can induce translocation of $\mathrm{p} 65 / \mathrm{NF}-\kappa \mathrm{B}$ into the nucleus and enhance the transcriptional activity of NF- $\mathrm{KB}$ in the presence of apoptotic stimuli ${ }^{[20]}$. Keel et al. discovered that thiopental inhibited NF- $\kappa \mathrm{B}$ in Jurkat cells via inhibition of the calmodulin-calcineurin pathway, and the NF- $\kappa B$ inhibitor gliotoxin could accelerate the spontaneous apoptosis and the proapoptotic effect of thiopental in Jurkat cells ${ }^{[18]}$.

Some researchers consider that NF- $\kappa \mathrm{B}$ controls the transcriptional activity of genes encoding the survival proteins. Besides, in lots of immune cells, active NF- $\kappa$ B has been shown to play a central role in regulating the expression of inflammatory cytokine genes. These cytokines, in turn, could inhibit apoptotic process possibly through activating NF- $\kappa \mathrm{B}$ in a positive-feedback loop ${ }^{[21]}$.

\section{$4 \quad \mathrm{NF}-\mathrm{\kappa B}$ in neurodegeneration}

4.1 In nervous system aging Aging of nervous system is 
a physiological event characterized by chronic and irreversible loss of neurons. Though this process has been known for decades, the potential mechanisms of different cell phenotype vulnerabilities, the age-related extracellular signals triggering cell death, and the intracellular pathways responsible for translating these signals into cell death programs, still require extensive investigation. The threshold separating the physiological and the pathological neuron death is always undetectable. Absent prominent signs of inflammatory response, neuron death during aging is believed to be associated, at least in part, with apoptosis $^{[16]}$.

Aged nervous system reveals impaired cognitive functions. These impairments are aggravated in several neurodegenerative diseases. As an oxidative stressor, hyperoxia triggers signaling cascades via changing promoter activity by transcription factors. Rassin $\mathrm{D}$ et al. suggested that chronic stress, in contrast to acute stress such as hyperoxia, may have different effects on NF- $\kappa \mathrm{B}$ basal activity levels. Simultaneously, the response to hyperoxia in aged basal forebrain is diminished ${ }^{[22]}$. Model for aging in the basal forebrain cholinergic system showed that the cognitive deficits associated with aging was owed to the neuron loss and the cholinergic function decrease of spared neurons ${ }^{[23]}$. The activation of NF- $\kappa B$ in the basal forebrain primary culture treated with hydrogen peroxide or TNF- $\alpha$ is predominantly restricted to cranial basal forebrain nerves (CBFNs), and NF- $\mathrm{BB}$ activation appears mainly affecting the p65 translocation into the nucleus, but not the p50 subunit.

\subsection{In oxidative stress and neurodegenerative disease} Oxidative stress which is implicated in several neurodegenerative diseases has impact on neurons and glial cells. NF- $\kappa \mathrm{B}$ activation is a part of recovery process posterier to acute oxidative stress ${ }^{[24]}$. Activation of NF- $\kappa \mathrm{B}$ may protect hippocampal neurons against oxidative-stressinduced apoptosis ${ }^{[6]}$. Meanwhile, NF- $\kappa \mathrm{B}$ is an oxygen-sensitive transcription factor and contributes to altered signaling events induced by hypoxia ${ }^{[25]}$. Preconditioning-evoked neuroprotection is mediated by reactive oxygen species (ROS) and NF- $\kappa \mathrm{B}^{[26]}$. Glutamate-induced apoptosis mainly depends on reactive oxygen to activate series of transcription factors. A prolonged exposure to glutamate $(24 \mathrm{~h})$ can produce a depletion of intracellular glutathione that, in astroglial cells, is a typical biochemical change of early astrocyte dysfunction, resulting in cell alterations in the gliosis.
These effects are initiated by the activation of $\alpha$-Amino-3hydroxy-5-methyl-4-isoxazoleproprionic acid / hydrobromide/kainic acid (AMPA/KA) receptor and nearly completely blocked by anti-oxidants. A research confirmed that glutathione-SH (GSH) content determined the oxidative response to glutamate injury in primary astrocyte cultures and NF- $\kappa B$ pathway was involved in this response ${ }^{[27]}$. By inducing manganese superoxide dismutase (Mn-SOD) production and suppressing peroxynitrite formation and membrane lipid peroxidation, NF- $\kappa \mathrm{B}$ plays an anti-apoptotic role in neurodegenerative conditions involving oxidative stress $^{[28]}$.

Recent findings indicate that NF- $\kappa$ B plays significant roles in disorders such as stroke, epilepsy, and Alzheimer's, Parkinson's and Huntington's diseases ${ }^{[29]}$. Immunohistochemical analysis of brain sections from Alzheimer's disease patients demonstrated that $\mathrm{NF}-\kappa \mathrm{B}$ was activated in most insulted areas of the brain ${ }^{[6]}$. Meanwhile, peroxynitrite and $\mathrm{NF}-\kappa \mathrm{B}$ are considered playing an anti-apoptotic role in the pathogenesis of neuronal degeneration in Alzheimer's disease $^{[26]}$. In Parkinson's disease patients, the number of neurons with NF- $\mathrm{kB}$-stained nuclei was 70 -fold higher than that in control group, revealing that the translocation of $\mathrm{NF}-\kappa \mathrm{B}$ to the nucleus is related to the pathophysiology of the disease ${ }^{[6]}$. Mutations in the parkin gene are a major cause of autosomal recessive Parkinson's disease. Henn IH et al. indicated that the E3 ubiquitin ligase parkin activated signaling through the $\mathrm{I} \kappa \mathrm{K} / \mathrm{NF}-\kappa \mathrm{B}$ pathway and that activation of this signaling cascade was causally linked to the neuroprotective potential of parkin. Inhibition of NF$\kappa \mathrm{B}$ activation by an $\mathrm{I} \kappa \mathrm{B}$ super-repressor or a kinase-inactive $I \kappa K \beta$ decreased the neuroprotective activity of parkin. Meanwhile, the ability of pathogenic parkin mutants to stimulate NF- $\kappa \mathrm{B}$-dependent transcription was reduced. Besides, parkin also interacted with and promoted degradation-independent ubiquitylation of NEMO/IкK- $\gamma$ and TNF receptor-associated factor 2 (TRAF2), the two critical

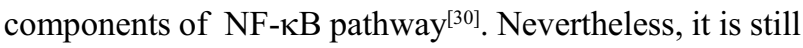
unclear whether activation of the c-Rel-dependent pathway reduces the neuronal vulnerability to amyloid-beta (Aא/ $\mathrm{Ab}$ ), a peptide involved in the pathogenesis of Alzheimer's disease. Some researchers discovered that c-Rel, a NF- $\kappa B$ factor, mediates the neuroprotective effect of metabotropic glutamate receptors type 5 (mGlu5) against $\mathrm{A} \beta$ toxicity ${ }^{[31]}$. $\mathrm{NF}-\kappa \mathrm{B}$ activation has shown to mediate excitotoxin-induced apoptosis in rat striatum and to encourage the neurotoxic- 
ity of $A \beta$. Furthermore, nerve growth factor (NGF) demonstrates to inhibit apoptosis by activating NF- $\mathrm{BB}$ with the subsequent inhibition of caspase- 8 and an increase of Bcl2 protein. Inhibition of NF- $\mathrm{KB}$-induced gene transcription lead to the NGF-resistant apoptosis in PC12 cells and potentiate the apoptotic damage mediated by $\mathrm{A} \beta$ peptide in neurons ${ }^{[32]}$.

\section{Summary}

At present, there are considerable researches about $\mathrm{NF}-\kappa \mathrm{B}$ and about the expression of NF- $\mathrm{B}$ following the brain injury or under some pathologic conditions. However, the effects of NF- $\mathrm{KB}$ on the pathways of cell death or survival remain controversial. It is true that persistent NF- $\kappa \mathrm{B}$ activation is essential for maintaining the growth and integrity of neurons ${ }^{[12,34]}$. Researches on brain ischemic models indicate that $\mathrm{NF}-\kappa \mathrm{B}$ can protect injured neurons from apoptosis in a distinct degree and thus NF- $\kappa \mathrm{B}$ displays direct or indirect repair effects on nervous tissues. However, some other studies suggest that NF- $\kappa \mathrm{B}$ does harm to nerve cells. For example, the infarct size diminished in p50 knockout mice after transient ischemia, indicating that NF- $\mathrm{KB}$ may induce ischemic cells' death ${ }^{[9,33]}$.

Researches focused on roles of NF- $\kappa \mathrm{B}$ in TBI are very few. There is no solid evidence yet to elucidate the differential roles of $\mathrm{NF}-\kappa \mathrm{B}$ in the core and peripheral regions of the injured site, or to distinguish the cells doomed to death

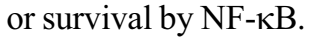

Reports also indicate that selective activation of different NF- $\kappa B$ dimers might have different regulatory effects on neuronal responses to acute or chronic insults to the CNS. Data displayed that augment of p65 may get a promotive while angment of p50 may get a depressant effect ${ }^{[24]}$. By the coordination of p65 subunit and p50 subunit, NF$\kappa \mathrm{B}$ can regulate transcriptions of various genes, including inflammatory genes, apoptosis genes, anti-apoptosis genes $B c l-2$ and $B c l-x L$, and etc. Opposite effects of NF- $\kappa B$ on neuron survival or death depend on activations of distinct NF- $\kappa \mathrm{B}$ factors. P65 is essential for glutamate-induced cell death, while c-Rel mediates pro-survival effects of interleukin-1 beta (IL-1 $\beta$ ).

Under bio-pathological conditions, the promotion or inhibition of cell death pathway depends on where and when NF- $\mathrm{BB}$ is activated. As an important controlling gene responsible for cell survival or death in the nerve system, $\mathrm{NF}-\kappa \mathrm{B}$ is a promising therapeutic target for nerve injury.
Moreover, the research related to NF- $\kappa \mathrm{B}$ has certain instructive significance for clinical diagnosis and treatment.

Acknowledgements: This work was supported by the National Natural Science Foundation of China (No. 30571909), the Youth Teacher's Research Foundation of Jiangsu Province, China (No. BU134701), and the Medical Development Foundation of Soochow University (No. EE134615).

\section{References:}

[1] Gilmore TD. Introduction to NF- $\kappa$ B: players, pathways, perspectives. Oncogene 2006, 25: 6680-6684.

[2] Vernon DO, Garbuzova-Davis S, Desjarlais T, Singh Rasile R, Sanberg PR, Willing AE, et al. Reduced Nuclear Factor kappa $B$ activation in dentate gyrus after active avoidance training. Brain Res 2006, 1104: 39-44.

[3] Kaltschmidt B, Widera D, Kaltschmidt C. Signaling via NF- $\kappa$ B in the nervous system. Biochim Biophys Acta 2005, 1745: 287-299.

[4] Mattson MP, Meffert MK. Roles for NF-kappaB in nerve cell survival, plasticity, and disease. Cell Death Differ 2006, 13: $852-860$

[5] Zhang W, Stanimirovic D. Current and future therapeutic strategies to target inflammation in stroke. Curr Drug Targets Inflamm Allergy 2002, 1: 151-166.

[6] Daily D, Vlamis-Gardikas A, Offen D, Mittelman L, Melamed E, Holmgren A, et al. Glutaredoxin protects cerebellar granule neurons from dopamine-induced apoptosis by dual activation of the ras-phosphoinositide 3-kinase and jun n-terminal kinase pathways. J Biol Chem 2001, 276: 21618-21626.

[7] Saito N, Courtois G, Chiba A, Yamamoto N, Nitta T, Hironaka $\mathrm{N}$, et al. Two carboxyl-terminal activation regions of EpsteinBarr virus latent membrane protein 1 activate NF- $\mathrm{BB}$ through distinct signaling pathways in fibroblast cell lines. J Biol Chem 2003, 278: 46565-46575.

[8] Nurmi A, Lindsberg PJ, Koistinaho M, Zhang W, Juettler E, Karjalainen-Lindsberg ML, et al. Nuclear factor-kappaB contributes to infarction after permanent focal ischemia. Stroke 2004, 35: 987-991.

[9] Zhang W, Potrovita I, Tarabin V, Herrmann O, Beer V, Weih $\mathrm{F}$, et al. Neuronal activation of NF- $\kappa \mathrm{B}$ contributes to cell death in cerebral ischemia. J Cereb Blood Flow Metab 2005, 25: 30-40.

[10] Domanska-Janik K, Bronisz-Kowalczyk A, Zajac H, Zablocka B. Interrelations between nuclear-factor kappa B activation, glial response and neuronal apoptosis in gerbil hippocampus after ischemia. Acta Neurobiol Exp (Wars) 2001, 61: 45-51.

[11] Pennypacker KR, Kassed CA, Eidizadeh S, Saporta S, Sanberg $\mathrm{PR}$, Willing AE. NF- $\mathrm{KB}$ p50 is increased in neurons surviving hippocampal injury. Exp Neurol 2001, 172: 307-319. 
[12] Duckworth EA, Butler T, Collier L, Collier S, Pennypacker KR. NF- $\kappa \mathrm{B}$ protects neurons from ischemic injury after middle cerebral artery occlusion in mice. Brain Res 2006, 1088: 167175 .

[13] Hang CH, Shi JX, Li JS, Wu W, Yin HX. Concomitant up regulation of nuclear factor-kB activity, proinflammatory cytokines and ICAM-1 in the injured brain after cortical contusion trauma in a rat model. Neurol India 2005, 53: 312-317.

[14] Tao L, Chen X, Qin Z, Bian S. Could NF- $\kappa B$ and caspase-3 be markers for estimation of post-interval of human traumatic brain injury? Forensic Sci Int 2006, 162: 174-177.

[15] Nomoto Y, Yamamoto M, Fukushima T, Kimura H, Ohshima K, Tomonaga M. Expression of nuclear factor kappa B and tumor necrosis factor alpha in the mouse brain after experimental thermal ablation injury. Neurosurgery 2001, 48: 158166.

[16] Uberti D, Grilli M, Memo M. Contribution of NF- $\kappa B$ and p53 in the glutamate-induced apoptosis. Int J Dev Neurosci 2000, 18: 447-454.

[17] Juravleva E, Barbakadze T, Mikeladze D, Kekelidze T. Creatine enhances survival of glutamate-treated neuronal/glial cells, modulates Ras/NF- $\kappa \mathrm{B}$ signaling, and increases the generation of reactive oxygen species. J Neurosci Res 2005, 79: 224-230.

[18] Dhandapani KM, Wade FM, Wakade C, Mahesh VB, Brann DW. Neuroprotection by stem cell factor in rat cortical neurons involves AKT and NFkappaB. J Neurochem 2005, 95: 919.

[19] Marini AM, Jiang X, Wu X, Tian F, Zhu D, Okagaki P, et al. Role of brain-derived neurotrophic factor and NF- $\kappa B$ in neuronal plasticity and survival: From genes to phenotype. Restor Neurol Neurosci 2004, 22: 121-130.

[20] Zhu Y, Culmsee C, Klumpp S, Krieglstein J. Neuroprotection by transforming growth factor-beta1 involves activation of nuclear factor-kappaB through phosphatidylinositol-3-OH kinase/Akt and mitogen-activated protein kinase-extracellular-signal regulated kinase1,2 signaling pathways. Neuroscience 2004, 123: 897-906.

[21] Keel M, Mica L, Stover J, Stocker R, Trentz O, Harter L. Thiopental-induced apoptosis in lymphocytes is independent of CD95 activation. Anesthesiology 2005, 103: 576-584.

[22] Toliver-Kinsky T, Rassin D, Perez-Polo JR. NF-kappaB activity decreases in basal forebrain of young and aged rats after hyperoxia. Neurobiol Aging 2002, 23: 899-905.

[23] Gu Z, Wortwein G, Yu J, Perez-Polo JR. Model for aging in the basal forebrain cholinergic system. Antioxid Redox Signal 2000, 2: 437-447.

[24] Gu Z, Cain L, Werrbach-Perez K, Perez-Polo JR. Differential alterations of $\mathrm{NF}-\kappa \mathrm{B}$ to oxidative stress in primary basal forebrain cultures. Int J Dev Neurosci 2000, 18: 185-192.

[25] Chau CH, Clavijo CA, Deng HT, Zhang Q, Kim KJ, Qiu Y, et al. Etk/Bmx mediates expression of stress-induced adaptive genes VEGF, PAI-1, and iNOS via multiple signaling cascades in different cell systems. Am J Physiol Cell Physiol 2005, 289: C444-C554.

[26] Ravati A, Ahlemeyer B, Becker A, Klumpp S, Krieglstein J. Preconditioning-induced neuroprotection is mediated by reactive oxygen species and activation of the transcription factor nuclear factor-кB. J Neurochem 2001, 78: 909-919.

[27] Caccamo D, Campisi A, Marini H, Adamo EB, Li Volti G, Squadrito $\mathrm{F}$, et al. Glutamate promotes $\mathrm{NF}-\kappa \mathrm{B}$ pathway in primary astrocytes: protective effects of IRFI 016, a synthetic vitamin E analogue. Exp Neurol 2005, 193: 377-383.

[28] Mattson MP, Goodman Y, Luo H, Fu W, Furukawa K. Activation of NF- $\kappa \mathrm{B}$ protects hippocampal neurons against oxidative stress-induced apoptosis: evidence for induction of manganese superoxide dismutase and suppression of peroxynitrite production and protein tyrosine nitration. J Neurosci Res 1997, 49: 681-697.

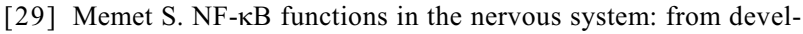
opment to disease. Biochem Pharmacol 2006, 72: 1180-1195.

[30] Henn IH, Bouman L, Schlehe JS, Schlierf A, Schramm JE, Wegener E, et al. Parkin mediates neuroprotection through activation of IêB kinase/nuclear factor- $\mathrm{\kappa B}$ signaling. J Neurosci 2007, 27: 1868-1878.

[31] Pizzi M, Sarnico I, Boroni F, Benarese M, Steimberg N, Mazzoleni G, et al. NF- $\mathrm{B}$ factor c-Rel mediates neuroprotection elicited by mGlu5 receptor agonists against amyloid $\beta$-peptide toxicity. Cell Death Differ 2005, 12: 761-772.

[32] Ramesh V, Thatte HS, McCarley RW, Basheer R. Adenosine and sleep deprivation promote $\mathrm{NF}-\kappa \mathrm{B}$ nuclear translocation in cholinergic basal forebrain. J Neurochem 2007, 100: 13511363 .

[33] Schneider A, Martin-Villalba A, Weih F, Vogel J, Wirth T, Schwaninger M. NF- $\kappa$ B is activated and promotes cell death in focal cerebral ischemia. Nat Med 1999, 5: 554-559.

[34] Kaltschmidt C, Kaltschmidt B, Neumann H, Wekerle H, Baeuerle PA. Constitutive NF- $\mathrm{BB}$ activity in neurons. Mol Cell Biol 1994, 14: 3981-3992. 


\section{$N F-\kappa B$ 在中枢神经系统损伤和修复中的作用}

杨丽，陶陆阳，陈溪萍

苏州大学医学院法医学教研室，苏州大学衰老与神经疾病实验室，苏州 215123

摘要: 细胞核因子 $-\kappa B($ nuclear factor kappa $B, N F-\kappa B$ ) 家族是 B 淋巴细胞核因子, 它能够与免疫球蛋白 $\kappa$ 链增 强子结合并增加各种基因的表达活性。NF- $\mathrm{kB}$ 通过典型和非典型途径的激活来控制和调节各种生理病理过程。在 中枢神经系统, NF- $\mathrm{kB}$ 调控炎症反应、神经损伤后的神经细胞调亡等, 它可以促进中风等缺血性脑损伤的脑梗 死面积和神经元死亡, 同时又对神经元的存活有重要影响。NF- $\mathrm{kB}$ 激活是神经康复的重要组成部分, 它能够保 护神经元免于由氧化应激和脑缺血诱导的神经元调亡和变性, 阻滞NF- $\mathrm{kB}$ 活性将影响它的神经保护机制。NF- $\mathrm{kB}$ 这种对神经元存活和死亡的双重效应取决于NF-KB激活的亚单位类型、激活所处的损伤位置以及损伤后修复的时 程 。

关键词: 中枢神经系统; 核因子 $-\kappa \mathrm{B}$; 神经损伤; 修复

\section{Retraction Statement}

Retraction: Zheng Z, Chen B. Effects of Pravastatin on neuroprotection and neurogenesis after cerebral ischemia in rats. Neuroscience Bulletin 2007, 23(4):189-197.

This paper has led to some dispute concerning authorization issue. The main work of this paper was done in Heidelberg University Germany, but not in the Burns Center, Xijing Hospital, The Fourth Military Medical University, Xi'an 710032, China where we are working. The copyright of this paper should belong to Heidelberg University Germany. So we hereby retract the paper from the journal, Medline/PubMed and other databases involved in China and abroad. We apologize to my colleagues in Heidelberg University Germany and editors of Neuroscience Bulletin. Creates inconveniently to the readers, we express deeply the apology!

Zhao ZHENG, BiCHEN

August, 30, 2007 